\title{
PRIMER COLOQUIO FRANCO-LATINOAMERICANO DE COMUNICACIÓN EMPRESARIAL
}

\author{
Por María José Larre Borges
}

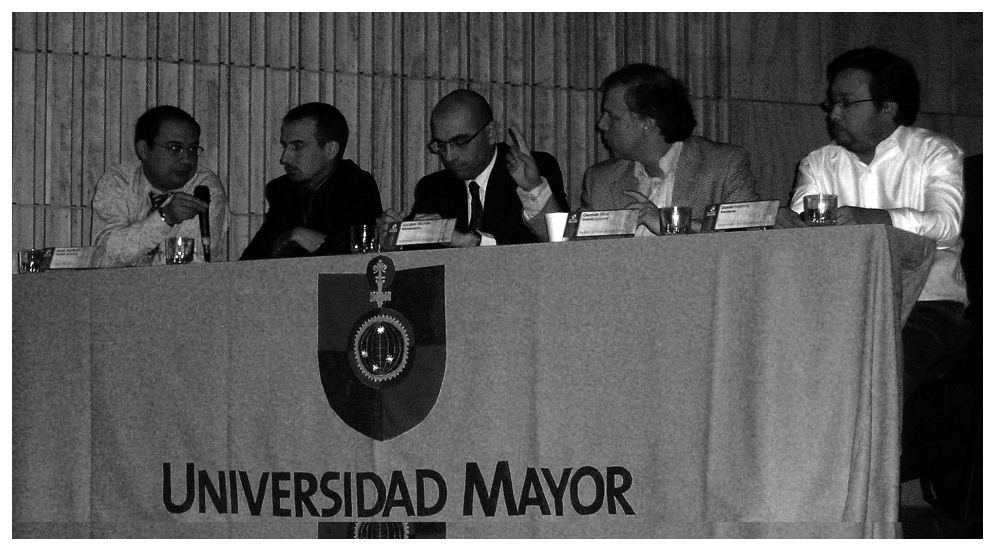

El 4 y 5 de noviembre de 2009 se realizó en la Universidad Mayor de Santiago de Chile el Primer coloquio franco-latinoamericano de Comunicación Empresarial, denominado "La comunicación como estrategia para dar valor a la empresa”. En él participaron comunicadores, docentes y estudiantes de diferentes países de América Latina, incluida una nutrida delegación uruguaya. Las conferencias fueron realizadas por académicos y consultores latinoamericanos y franceses; por la Universidad Católica expuso Mónica Arzuaga.

María José Larre Borges::

(Montevideo, 1964).

Es docente y comunicadora de la

Licenciatura en

Comunicación Social de

la Universidad Católica del Uruguay. Es profesora del Taller de Escritura III y tutora del Seminario de

Memoria de Grado "La mediatización de la política uruguaya".

Foto gentileza de Fiorella Musitelli cación para directivos. Por otra parte, en los debates sobre la RSE, fueron especialmente enfatizadas las acciones vinculadas al cuidado y respeto del ambiente.

En una crisis institucional, no solo se juega la reputación e imagen de una organización, sino que también se pone a prueba su capacidad real de gestionar sus comunicaciones. La elaboración de una estrategia consecuente, consistente, oportuna y adecuada fue central en los acercamientos a este tema. Bajo el nombre de "factor usuario", los participantes discutieron el uso de las nuevas tecnologías por parte de los diferentes públicos, que posibilita nuevas formas de empoderamiento: un "efecto enjambre" de navegantes organizados que opinan y, muchas veces, se adelantan a las estrategias organizacionales.

Las conclusiones del coloquio fueron ricas y variadas. De acuerdo con ellas, los desafíos de la comunicación organizacional se centrarán en los siguientes principios: innovación y creatividad, ética y transparencia, una política de comunicación integral, un monitoreo constante de la opinión pública y la sustitución de una visión "mecanicista” de la comunicación por una visión global y estratégica.:- 